\title{
Association of smoking frequency and cigarette consumption with obesity in Korean adolescents
}

\author{
Jong-Hyuck K ${ }^{1}$, Wi-Young $\mathrm{S}^{2}$ \\ Department of Sport Education in Living, Bucheon University, Bucheon, Korea. wowso@swu.ac.kr
}

\begin{abstract}
The purpose of this study was to examine whether smoking frequency and cigarette consumption were related with obesity in Korean adolescents. A total of 72,399 adolescents from 1st grade middle-school to 3rd grade high-school participated in the 5th Korea Youth Risk Behavior Web-based Survey (KYRBWS) project in 2009. The relationship between the body mass index (BMI), smoking frequency, and cigarette consumption was assessed using multivariate logistic regression analysis after adjusting for covariate variables like age, frequency of alcohol consumption and severe alcohol intoxication, amount of alcohol consumed, parents' education level, economic status, sedentary activities during the week, mental stress, sleep duration, frequency of vigorous and moderate physical activities, and muscular strength exercises during the week. We concluded that both smoking frequency and cigarette consumption had positive effects with regard to weight loss in adolescents. However, because smoking has negative side effects on general health, including an increase in abdominal fat and morbidity rates of obesity-related diseases, we recommend that adolescents should not smoke (Tab. 3 , Ref. 26). Full Text in PDF www.elis.sk.

Key words: adolescent, Korea youth risk behavior web-based survey, obesity, smoking, cigarette.
\end{abstract}

In recent times, obesity has become a serious social and public health issue in Korea. In 2009, the Korea National Health and Nutrition Examination Survey-IV (KNHANES-IV) reported that $5.0 \%$ and $11.3 \%$ of adolescents are already overweight and obese, respectively, and that the prevalence of obesity is increasing with age (1). People in the $20 \mathrm{~s}, 30 \mathrm{~s}, 40 \mathrm{~s}, 50 \mathrm{~s}, 60 \mathrm{~s}$, and over-70s age groups have a $29.0 \%, 38.5 \%, 41.9 \%, 43.4 \%, 32.2 \%$, and 19.9 $\%$ risk, respectively, of becoming obese (1).

Obesity is known to induce various adverse health effects such as cardiac disease, stroke, diabetes, musculoskeletal disorders, and some cancers (endometrial, breast, and colon cancers) (2). Moreover, because approximately $80 \%$ of the obese adolescents grow into obese adults, it is important to prevent obesity during adolescence itself (3-4).

It is clear that sedentary lifestyle and unhealthy eating habits have contributed to an increase in the prevalence of obesity (5-6). Furthermore, obesity is also affected by drug use, cigarette smoking, and alcohol consumption. Therefore, a large number of studies are being carried out to determine the side effects associated with these habits (7).

Furthermore, smoking is the primary risk factor for pulmonary diseases, including lung cancer and other malignancies, chronic obstructive pulmonary disease, and cardiovascular disorders (8).

${ }^{1}$ Department of Sport Education in Living, Bucheon University, Bucheon, Korea, and ${ }^{2}$ Department of Human Movement Science, Seoul Women's University, Seoul, Korea

Address for correspondence: Wi-Young So, Department of Human Movement Science, Seoul Women's University, 621 Hwarangro, Nowon-Gu, Seoul 139-774, Korea.

Phone: +82.2 .9705683 , Fax: +82.2 .9705980$
Many studies have reported that smoking does not cause longterm weight loss; however, whether it worsens obesity or results in long-term weight-loss is still controversial. Canoy et al (2005) showed that current smokers have larger waistlines than past smokers and nonsmokers do (9). However, Stavropoulos-Kalinoglou et al (2008) showed that smoking is associated with a decreased body mass index (BMI) (10); Metsios et al (2008) reported that cigarette smoking significantly increases the basal metabolic rate (11), and Chou et al (2004) reported that reduction in smoking leads to weight gain (12).

A Korean study reported that an increase in cigarette consumption increases abdominal obesity in adults even when the BMI of these smokers is lower than that of nonsmokers (13). However, only a few studies have examined the relationship between smoking and obesity (13-14). Furthermore, although regional studies have been performed on this issue, no nationwide study has ever been performed on Korean adolescents in this regard. Therefore, the purpose of this study was to examine whether smoking frequency and cigarette consumption were related with obesity in Korean adolescents throughout the country.

\section{Methods}

\section{Subject}

The 5th Korea Youth Risk Behavior Web-based Survey (KYRBWS), a retrospective cohort study, was conducted using a complex sample design, involving stratification, clustering, and multistage sampling; this nationwide school-based survey was conducted by the Korea Centers for Disease Control and Prevention $(\mathrm{KCDCP})$ to evaluate the prevalence of health-risk behavior 
among adolescent students in Korea (15). This study involved students from 400 middle schools and 400 high schools and evaluated the association of smoking frequency and cigarette consumption with obesity in Korean adolescents, taking into account potential covariate variables.

Participated students were assigned unique identification numbers by classroom teachers. The students accessed the survey Web page by using their ID numbers and responded to a question about their willingness to participate. Willing participants self-administered the questionnaire anonymously at the school, and those unwilling did not progress further. The KYRBWS V was administered to a nationally representative study and as the KYRBWS V did not collect private information, ethical approval was not required.

The response rate of this study was $97.6 \%(n=75,066)$; students who were absent for long periods and students with dyslexia and dysgraphia were excluded from this study. Thus, 72,399 students participated in this study.

\section{Independent variables}

The participants were asked to self-record their heights and weights; BMI $\left(\mathrm{kg} / \mathrm{m}^{2}\right)$ was calculated for each participant by using their respective heights and weights. In accordance with the World Health Organization's (WHO) Asia-Pacific standard of obesity, individuals with BMIs of $<23, \geq 23-<25$, and $\geq 25 \mathrm{~kg} / \mathrm{m}^{2}$ were classified into normal, overweight, and obese groups, respectively (16).

\section{Dependent variables}

Self-reported smoking frequency and cigarette consumption were evaluated for each participant by asking them the following 3 questions: (Q1) "Do you smoke?," with the response options "1) No" and "2) Yes." A response of "never smoked" was considered as "No". (Q2) "In the last month, how often have you smoked more than 1 cigarette?," with the response options "1) No," "2)1-2 cigarettes per month," "3) 3-5 cigarettes per month," "“4) 6-9 cigarettes per month," "5) 10-19 cigarettes per month," and "6) 20-30 cigarettes per month." A response of "past smoked" was considered as "No". (Q3) "In the last month, how many cigarette(s) have you had on an average per day?," with the response options " 1 ) $<1$ cigarette per day," "2) 1 cigarette per day," "3) 2-5 cigarettes per day," "4) 6-9 cigarettes per day," "5) 10-19 cigarettes per day," and "6) $\geq 20$ cigarettes per day."

\section{Covariate variables}

1) Participant ages: the participant age defined by the KYRBWS was used without any modifications.

2) Frequency of drinking: the possible responses ranged from 1 (never) to 7 (everyday).

3) Alcohol consumption: the possible responses ranged from 1 ( $<1$ bottle of beer) to 5 ( $\geq 4$ bottles of beer).

4) Frequency of severe alcohol intoxication: the possible responses ranged from 1 (no) to 4 ( $>5$ times per month).

5) Parents' education level: the possible responses ranged from 1 (middle school or lower) to 3 (college or higher).

6) Economic status: the possible responses ranged from 1 (very rich) to 5 (very poor).
7) Frequency of vigorous physical activities, such as digging, aerobics, heavy lifting, or fast cycling during the week: the American College of Sports Medicine (ACSM) recommends that such activities be performed at least 3 times a week (17). On the basis of this recommendation and the frequency of vigorous physical activities performed during the week, the participants were divided into 2 groups, i.e., group 1 (yes; vigorous physical activity performed $\geq 3$ times per week) and group 2 (no; vigorous physical activity performed $<3$ times per week).

8) Frequency of moderate physical activities, such as bicycling at a regular pace, carrying light loads, or playing doubles tennis during the week: the ACSM recommends that such activities be performed at least 5 times a week (17). On the basis of this recommendation and the frequency of moderate physical activities performed during the week, the participants were divided into 2 groups, i.e., 1 (yes) and 2 (no).

9) Frequency of muscular strength exercises, such as sit-ups, push-ups, and weight lifting, during the week: the ACSM recommends that such exercises be performed at least 2 times a week (17). On the basis of this recommendation and the frequency of muscular strength exercises performed during the week, the participants were divided into 2 groups, i.e., 1 (yes) and 2 (no).

10) Sedentary activities like playing computer games, watching television, and using the internet during weekdays and weekends: Youth Risk Behavior Surveillance (YRBS)-United State recommends that such activities be limited to less than 3 hours per day (18). On the basis of this recommendation and the frequency of sedentary activities performed in the week, the participants were divided into 2 groups, i.e., 1 (yes) and 2 (no).

11) Mental stress: the possible responses ranged from 1 (very high) to 5 (none).

12) Sleep duration: the possible responses ranged from $1(\leq 4$ hours/day) to 6 ( $\geq 8$ hours/day).

\section{Statistical analysis}

The descriptive data are presented in terms of mean and standard deviation (mean $\pm \mathrm{SD}$ ). Multivariate logistic regression analyses were conducted to determine whether smoking frequency and cigarette consumption were related with BMI after adjusting for covariate variables. Statistical significance was set at $\mathrm{p}<0.05^{*}$, $\mathrm{p}<0.01^{* *}$, and $\mathrm{p}<0.001^{* * *}$, and all analyses were performed using SPSS ver. 12.0(SPSS, Chicago, IL, USA).

\section{Results}

\section{Characteristic of subjects}

The characteristics of the participants are shown in Table 1. The average age of the boys and girls participating in this study was $15.00 \pm 1.73$ and $15.12 \pm 1.77$ years, respectively; their average height was $169.58 \pm 8.19$ and $160.08 \pm 5.39 \mathrm{~cm}$, respectively; their average weight was $60.14 \pm 11.72$ and $51.47 \pm 7.67 \mathrm{~kg}$, respectively; and their average BMI was $20.80 \pm 3.21$ and $20.05 \pm 2.58$ $\mathrm{kg} / \mathrm{m}^{2}$, respectively. According to their respective BMI, the boys and girls were classified as being normal weight $(29,404(77.1 \%)$ and 29,667 (86.6\%), respectively), overweight (4,382 (11.5\%) 
Tab. 1. Characteristics of subjects (mean \pm SD).

\begin{tabular}{|c|c|c|c|c|}
\hline \multicolumn{2}{|l|}{ Variables } & $\begin{array}{c}\text { Boys } \\
(\mathrm{n}=38.152)\end{array}$ & $\begin{array}{c}\text { Girls } \\
(\mathrm{n}=34.247)\end{array}$ & $\begin{array}{c}\text { Total } \\
(\mathrm{n}=72.399)\end{array}$ \\
\hline \multicolumn{2}{|l|}{ Age (years) } & $15.00 \pm 1.73$ & $15.12 \pm 1.77$ & $15.06 \pm 1.75$ \\
\hline \multicolumn{2}{|l|}{ Height $(\mathrm{cm})$} & $169.58 \pm 8.19$ & $160.08 \pm 5.39$ & $165.09 \pm 8.46$ \\
\hline \multicolumn{2}{|l|}{ Weight (kg) } & $60.14 \pm 11.72$ & $51.47 \pm 7.67$ & $56.04 \pm 10.91$ \\
\hline \multicolumn{2}{|l|}{$\operatorname{BMI}\left(\mathrm{kg} / \mathrm{m}^{2}\right)$} & $20.80 \pm 3.21$ & $20.05 \pm 2.58$ & $20.45 \pm 2.95$ \\
\hline \multirow{3}{*}{$\begin{array}{l}\text { Weight state } \\
\mathrm{n}(\%)\end{array}$} & Normal weight $(\mathrm{BMI}<23)$ & $29404(77.1)$ & $29667(86.6)$ & $59071(81.6)$ \\
\hline & Over weight $(23 \leq \mathrm{BMI}<25)$ & $4382(11.5)$ & $2967(8.7)$ & $7349(10.2)$ \\
\hline & Obese $(25 \leq \mathrm{BMI})$ & $4366(11.4)$ & $1613(4.7)$ & $5979(8.3)$ \\
\hline \multirow{5}{*}{$\begin{array}{l}\text { Economic status } \\
\mathrm{n}(\%)\end{array}$} & Very rich & $2691(7.1)$ & $1337(3.9)$ & $4028(5.6)$ \\
\hline & Rich & $8768(23.0)$ & $6719(19.6)$ & $15487(21.4)$ \\
\hline & Average & $17229(45.2)$ & $17259(50.4)$ & $34488(47.6)$ \\
\hline & Poor & $6890(18.1)$ & $6825(19.9)$ & $13715(18.9)$ \\
\hline & Very poor & $2574(6.7)$ & $2107(6.2)$ & $4681(6.5)$ \\
\hline \multirow{2}{*}{$\begin{array}{l}\text { City size } \\
\mathrm{n}(\%)\end{array}$} & Large cities & $20252(53.1)$ & $17708(51.7)$ & $37960(52.4)$ \\
\hline & Middle-sized cities & $13303(34.9)$ & $12153(35.5)$ & $25456(35.2)$ \\
\hline \multirow{4}{*}{$\begin{array}{l}\text { Grade } \\
\mathrm{n}(\%)\end{array}$} & $1^{\text {st }}$ grade middle-school & $6711(17.6)$ & $5615(16.4)$ & $12326(17.0)$ \\
\hline & $2^{\text {nd }}$ grade middle-school & $6722(17.6)$ & $5727(16.7)$ & $12449(17.2)$ \\
\hline & $3^{\text {rd }}$ grade middle-school & $6767(17.7)$ & $5615(16.4)$ & $12382(17.1)$ \\
\hline & $1^{\text {st }}$ grade high-school & $6626(17.4)$ & $5369(15.7)$ & $11995(16.6)$ \\
\hline
\end{tabular}

Tab. 2. The multivariate logistic regression analyses of smoking frequency and cigarette consumption for the overweight group compared to the normal weight group in Korean adolescents.

\begin{tabular}{|c|c|c|c|c|c|c|c|}
\hline \multirow[t]{3}{*}{ Category } & & \multicolumn{6}{|c|}{ Overweight vs normal weight } \\
\hline & & \multicolumn{3}{|c|}{ Boys } & \multicolumn{3}{|c|}{ Girls } \\
\hline & & OR & $95 \% \mathrm{CI}$ & p-value & OR & $95 \% \mathrm{CI}$ & p-value \\
\hline \multirow[t]{7}{*}{ Smoking frequency } & Never smoked & Ref & & & Ref & & \\
\hline & Past smoked & 0.905 & $0.829-0.988$ & $<0.025^{*}$ & 1.035 & $0.923-1.162$ & $<0.555$ \\
\hline & $1-2$ per month & 0.794 & $0.645-0.978$ & $<0.030^{*}$ & 0.927 & $0.686-1.252$ & $<0.621$ \\
\hline & $3-5$ per month & 0.924 & $0.692-1.235$ & $<0.593$ & 1.410 & $0.956-2.080$ & $<0.083$ \\
\hline & $6-9$ per month & 0.854 & $0.610-1.195$ & $<0.357$ & 0.948 & $0.543-1.656$ & $<0.851$ \\
\hline & $10-19$ per month & 0.878 & $0.659-1.170$ & $<0.375$ & 1.300 & $0.831-2.034$ & $<0.251$ \\
\hline & 20-30 per month & 0.686 & $0.602-0.781$ & $<0.001 * * *$ & 0.713 & $0.565-0.898$ & $<0.004 * *$ \\
\hline \multirow[t]{7}{*}{ Cigarette consumption } & Never smoked & Ref & & & Ref & & \\
\hline & Past smoked & 0.905 & $0.829-0.988$ & $<0.025^{*}$ & 1.035 & $0.923-1.162$ & $<0.555$ \\
\hline & $<1$ cigarette per day & 0.784 & $0.637-0.965$ & $<0.021 *$ & 1.147 & $0.857-1.535$ & $<0.357$ \\
\hline & 1 cigarette per day & 0.763 & $0.575-1.013$ & $<0.061$ & 0.983 & $0.622-1.552$ & $<0.941$ \\
\hline & $2-5$ cigarettes per day & 0.846 & $0.726-0.986$ & $<0.032 *$ & 0.813 & $0.626-1.057$ & $<0.123$ \\
\hline & 6-9 cigarettes per day & 0.628 & $0.515-0.765$ & $<0.001 * * *$ & 0.674 & $0.472-0.963$ & $<0.030 *$ \\
\hline & $\geq 20$ cigarettes per day & 0.776 & $0.566-1.064$ & $<0.116$ & 1.026 & $0.533-1.974$ & $<0.939$ \\
\hline
\end{tabular}

OR; Odd Ratio, CI; Confidence Interval

$* \mathrm{p}<0.05, * * \mathrm{p}<0.01, * * * \mathrm{p}<0.001$, tested by multivariate logistic regression analysis (adjusting for covariate variables such as age, frequency of alcohol consumption and severe alcohol intoxication, amount of alcohol consumed, parents' education level, economic status, sedentary activities during the week, mental stress, sleep duration, frequency of vigorous and moderate physical activities, and muscular strength exercises during the week)

and $2,967(8.7 \%)$, respectively), and obese $(4,366(11.4 \%)$ and $1,613(4.7 \%)$, respectively).

The economic status of the boys and girls was as follows: $2,691(7.1 \%)$ boys and 1,337 (3.9\%) girls were very rich; 8,768 (23.0 \%) boys and 6,719 (19.6\%) girls were rich; 17,229 (45.2\%) boys and 17,259 (50.4\%) girls had an average economic status; $6,890(18.1 \%)$ boys and 6,825 (19.9\%) girls were poor; and 2,574 $(6.7 \%)$ boys and 2,107 (6.2\%) girls were very poor. The data for city sizes were as follows: 20,252 (53.1\%) boys and 17,708 (51.7 $\%)$ girls lived in large cities; 13,303 (34.9\%) boys and 12,153 (35.5\%) girls lived in middle-sized cities; and 4,597 (12.0\%) boys and 4,386 (12.8\%) girls lived in small-sized cities. The grades achieved at school were as follows: 6,711 (17.6\%) boys and 5,615
(16.4\%) girls were in 1st grade middle-school; 6,722 (17.6\%) boys and 5,727 (16.7\%) girls were in 2nd grade middle-school; $6,767(17.7 \%)$ boys and 5,615 (16.4\%) girls were in 3rd grade middle-school; 6,626 (17.4\%) boys and 5,369 (15.7\%) girls were in 1st grade high-school; 5,889 (15.4\%) boys and 6,102 (17.8\%) girls were in 2nd grade high-school; and 5,437 (14.3\%) boys and $5,819(17.0 \%)$ girls were in 3rd grade high-school.

\section{The multivariate logistic regression analyses}

Multivariate logistic regression analyses of smoking frequency and cigarette consumption for the overweight and normal weight groups and for the obese and normal weight groups of Korean adolescents are shown in Tables 2 and 3, respectively. The data 
Tab. 3. The multivariate logistic regression analyses of smoking frequency and cigarette consumption for the obese group compared to the normal-weight group in Korean adolescents.

\begin{tabular}{|c|c|c|c|c|c|c|c|}
\hline \multirow[t]{3}{*}{ Category } & & \multicolumn{6}{|c|}{ Obese Vs. normal-weight } \\
\hline & & \multicolumn{3}{|c|}{ Boys } & \multicolumn{3}{|c|}{ Girls } \\
\hline & & OR & $95 \% \mathrm{CI}$ & p-value & OR & $95 \% \mathrm{CI}$ & p-value \\
\hline \multirow[t]{7}{*}{ Smoking frequency } & Never smoked & Ref & & & Ref & & \\
\hline & Past smoked & 0.948 & $0.869-1.035$ & $<0.233$ & 0.974 & $0.836-1.135$ & $<0.736$ \\
\hline & $1-2$ per month & 0.978 & $0.803-1.192$ & $<0.827$ & 1.099 & $0.768-1.573$ & $<0.606$ \\
\hline & $3-5$ per month & 0.853 & $0.624-1.167$ & $<0.319$ & 0.796 & $0.416-1.521$ & $<0.489$ \\
\hline & $6-9$ per month & 1.261 & $0.933-1.706$ & $<0.131$ & 1.600 & $0.893-2.869$ & $<0.114$ \\
\hline & $10-19$ per month & 1.104 & $0.840-1.452$ & $<0.477$ & 1.076 & $0.575-2.012$ & $<0.819$ \\
\hline & 20-30 per month & 0.798 & $0.702-0.908$ & $<0.001 * *$ & 0.492 & $0.348-0.694$ & $<0.001 * * *$ \\
\hline \multirow[t]{8}{*}{ Cigarette consumption } & Never smoked & Ref & & & Ref & & \\
\hline & Past smoked & 0.948 & $0.869-1.035$ & $<0.233$ & 0.974 & $0.836-1.135$ & $<0.736$ \\
\hline & $<1$ cigarette per day & 1.051 & $0.870-1.271$ & $<0.605$ & 1.166 & $0.804-1.692$ & $<0.418$ \\
\hline & 1 cigarette per day & 1.064 & $0.823-1.376$ & $<0.635$ & 0.740 & $0.376-1.456$ & $<0.383$ \\
\hline & $2-5$ cigarettes per day & 0.845 & $0.721-0.990$ & $<0.037^{*}$ & 0.872 & $0.627-1.213$ & $<0.416$ \\
\hline & 6-9 cigarettes per day & 0.801 & $0.664-0.967$ & $<0.021^{*}$ & 0.336 & $0.181-0.625$ & $<0.001 * *$ \\
\hline & $10-19$ cigarettes per day & 0.852 & $0.682-1.063$ & $<0.156$ & 0.538 & $0.278-1.041$ & $<0.066$ \\
\hline & $\geq 20$ cigarettes per day & 0.653 & $0.457-0.933$ & $<0.019^{*}$ & 0.811 & $0.317-2.074$ & $<0.662$ \\
\hline
\end{tabular}

OR; Odd Ratio, CI; Confidence Interval

$* \mathrm{p}<0.05, * * \mathrm{p}<0.01, * * * \mathrm{p}<0.001$, tested by multivariate logistic regression analysis (adjusting for covariate variables such as age, frequency of alcohol consumption and severe alcohol intoxication, amount of alcohol consumed, parents' education level, economic status, sedentary activities during the week, mental stress, sleep duration, frequency of vigorous and moderate physical activities, and muscular strength exercises during the week)

presented in the tables show the prevalence of overweight and obesity in Korean adolescents after adjusting for covariate variables such as age, frequency of alcohol consumption and severe alcohol intoxication, amount of alcohol consumed, parents' education level, economic status, sedentary activities during the week, mental stress, sleep duration, frequency of vigorous and moderate physical activities, and muscular strength exercises during the week.

For boys, the odds ratios (ORs) $(95 \%$ confidence interval $[\mathrm{CI}])$ between becoming overweight and frequency of smoking were 0.905 (range, $0.829-0.988 ; \mathrm{p}=0.025$ ) for past smokers; 0.794 (range, $0.645-0.978 ; \mathrm{p}=0.030$ ) for boys who smoked $1-2$ cigarettes per month; and 0.686 (range, $0.602-0.781 ; p<0.001$ ) for boys who smoked 20-30 cigarettes per month. The ORs between becoming overweight and cigarette consumption were 0.784 (range, $0.637-0.965 ; \mathrm{p}=0.021$ ) for $<1$ cigarette per day; 0.846 (range, $0.726-0.986 ; \mathrm{p}=0.032$ ) for $2-5$ cigarettes per day; 0.628 (range, $0.515-0.765 ; \mathrm{p}<0.001$ ) for 6-9 cigarettes per day; and 0.636 (range, $0.504-0.803 ; \mathrm{p}<0.001$ ) for $10-19$ cigarettes per day (Tab. 2). The OR (95\% CI) between becoming obese and frequency of smoking was 0.798 (range, $0.702-0.908 ; p=0.001$ ) for 20-30 cigarettes per month. The ORs between becoming obese and cigarette consumption were 0.845 (range, $0.721-0.990 ; \mathrm{p}=$ 0.037 ) for $2-5$ cigarettes per day; 0.801 (range, 0.664-0.967; $\mathrm{p}=$ 0.021 ) for 6-9 cigarettes per day; and 0.653 (range, 0.457-0.933; $\mathrm{p}=0.019$ ) for $\geq 20$ cigarettes per day (Tab. 3 ).

For girls, the OR $(95 \% \mathrm{CI})$ between becoming overweight and smoking frequency was 0.713 (range, $0.565-0.898 ; \mathrm{p}=0.004$ ) for 20-30 cigarettes per month. The OR between becoming overweight and cigarette consumption was 0.674 (range, 0.472-0.963; p = 0.030 ) for $6-9$ cigarettes per day (Tab. 2). The OR (95\% CI) between becoming obese and smoking frequency was 0.492 (range, $0.348-0.694 ; \mathrm{p}<0.001$ ) for $20-30$ cigarettes per month. The OR between becoming obese and cigarette consumption was 0.336 (range, $0.181-0.625 ; \mathrm{p}=0.001$ ) for $6-9$ cigarettes per day (Tab. 3 ).

\section{Discussion}

The purpose of this study was to examine whether smoking frequency and cigarette consumption were related to obesity in Korean adolescents. This study indicated that smoking frequency and cigarette consumption had a positive effect on weight loss in adolescents even after adjusting for covariate variables.

Smoking is reported to increase the levels of hormone leptin, which controls fat distribution and food consumption (19-20), and decreases the levels of hypothalamic neuropeptide-Y (NPY), which controls the appetite (21-22). Furthermore, smoking also increases the levels of thyroid hormones, such as epinephrine and norepinephrine, which increase energy expenditure during daily life activities (23-24). Thus, the results of this study showed a natural outcome and supported the results obtained in previous studies, which indicate that smoking is associated with a reduction in BMI (10-12). However, previous Korean studies have reported that smoking negatively affects abdominal fat levels and increases the morbidity rate of obesity-related diseases (13-14), even though smokers weigh lesser than nonsmokers do. This study, however, did not provide any information whether smoking was related to abdominal fat levels and with increased morbidity rate of obesityrelated diseases in Korean adolescents. Therefore, further welldesigned studies should be performed in the future to determine the effects of smoking on Korean adolescents.

Interestingly, smoking-associated BMI reduction is observed more in boys than in girls. This might be because boys secrete higher levels of hormones like epinephrine and norepinephrine during smoking, owing to the gender-related differences amongst boys and girls (25).

Stavropoulos-Kalinoglou et al (2008) reported that heavy smoking appeared to be associated with a reduction in the lean body mass (10). Our results show that the BMI of boys decreased with an increase in cigarette consumption. Severe smokers may have a more 
decreased BMI because of the higher reduction in lean body mass. We hope that further well-designed studies are undertaken to elucidate the relationship between severe smoking and reduced lean body mass.

Our study has some limitations. First, this study was conducted online, and the participants were asked to self-record their heights and weights. It is possible that the level of obesity that was measured would be relatively low, because adolescents have a tendency to exhibit an increase in height and decrease in weight (26). Second, information regarding the economic status was obtained from the adolescents and not from the parents, and hence, it can be inaccurate. Third, because this was a retrospective cohort study, it does not provide definitive evidence of causality or directionality but does provide their interrelationship. However, this study is different from the previous small regional case studies because it investigated adolescents from the entire country (Korea), with a sample population of 72,399 . Therefore, our study is one of the representative studies on the relationship between smoking and obesity in Korean adolescents.

\section{Conclusion}

We concluded that both smoking frequency and cigarette consumption had positive effects on weight loss in adolescents. However, because smoking has negative side effects on general health, including increase in abdominal fat and morbidity rates due to obesity-related diseases, we recommend that adolescents should not smoke.

\section{References}

1. Korea Centers for Disease Control and Prevention. Korea Health Statistics 2009: Korea National ealth and Nutrition Examination Survey (KNHANESIV-3). Korea Centers for Disease Control and Prevention, 2010.

2. World Health Organization: Obesity and Overweight. Global Strategy on Diet, Physical Activity and Health. 2011. http://www.who.int/mediacentre/factsheets/fs311/en/

3. Kvaavik E, Tell GS, Klepp KI. Predictors and tracking of body mass index from adolescence into adulthood: Follow-up of 18 to 20 years in the Oslo Youth Study. Arch Pediat Adolesc Med 2003; 157 (12): 1212-1218.

4. Daniels SR, Arnett DK, Eckel RH, Gidding SS, Hayman LL, Kumanyika S, Robinson TN, Scott BJ. Overweight in children and adolescents pathophysiology, consequences, prevention, and treatment. Circulation 2005; 111: 1999-2012.

5. Canoy D, Bundred P. Obesity in children. Clin Evid (Online) 2011; pii: 0325.

6. Park YS, Lee DH, Choi JM, Kang YJ, Kim CH. Trend of obesity in school age children in Seoul over the past 23 years. Korean J Pediat 2004; 47 (3): 247-257.

7. Thomas AW, Albert JS. Handbook of obesity treatment ( $3^{\text {rd }}$ ed.). New York: Guilford Press. USA, 2002.

8. Fielding JE. Smoking: health effects and control (1). N Engl J Med 1985; 313: 491-498.

9. Canoy D, Wareham N, Luben R, Welch A, Bingham S, Day N, Khaw KT. Cigarette smoking and fat distribution in 21,828 British men and women: A population-based study. Obesity Res 2005; 13: 1466-1475.
10. Stavropoulos-Kalinoglou A, Metsios GS, Panoulas VF, Douglas KM, Nevill AM, Jamurtas AZ, Kita M, Koutedakis Y, Kitas GD. Cigarette smoking associates with body weight and muscle mass of patients with rheumatoid arthritis: a cross-sectional, observational study. Arthritis Res Ther 2008; 10 (3): R59.

11. Metsios GS, Stavropoulos-Kalinoglou A, Nevill AM, Douglas KM, Koutedakis Y, Kitas GD. Cigarette smoking significantly increases basal metabolic rate in patients with rheumatoid arthritis. Ann Rheum Dis 2008; 67 (1): 70-73.

12. Chou SY, Grossman M, Saffer H. An economic analysis of adult obesity: results from the Behavioral Risk Factor Surveillance System. J Health Econ 2004; 23 (3): 565-587.

13. Lee KM, Kim HY, Jung SP, Kim JH, Song CH.Effects of Cigarette Smoking on Abdominal Fatness. J Korean Acad Fam Med 2000; 21 (9): 1172-1179.

14. Kwon JD, Kim BT, Kim KM, Park SB, Kim E, Chang CS, Kim BY, Joo NS. The Relationship between Cigarette Smoking and Obesity in the Adolescents. J Korean Aca Fam Med 2010; 31 (5): 369-376.

15. Korea Centers for Disease Control and Prevention. The Statistics of $5^{\text {th }}$ Korea Youth Risk Behavior Web-based Survey(KYRBWS) in 2009: 2010.11.02.

16. WHO/IASO/IOTF. The Asia-Pacific perspective: redefining obesity and its treatment. Health Communications Australia: Melbourne. 2000.

17. ACSM. ACSM's guidelines for exercise testing and prescription 8th ed. Lippincott Williams \& Wilkins. 2009.

18. Eaton DK, Kann L, Kinchen S, Shanklin S, Ross J, Hawkins J, Harris WA, Lowry R, McManus T, Chyen D, Lim C, Whittle L, Brener ND, Wechsler H. Youth Risk Behavior Surveillance-United State, 2009. Morbidity and mortality weekly report. Surv Summ 2010; 59: SS-5.

19. Nicklas BJ, Tomoyasu N, Muir J, Goldberg AP. Effects of cigarette smoking and its cessation on body weight and plasma leptin levels. Metabolism 1999; 48: 804-808.

20. Chen H, Hansen MJ, Jones JE, Vlahos R, Bozinovski S, Anderson GP, Morris MJ. Cigarette smoke exposure reprograms the hypothalamic neuropeptide Y axis to promote weight loss. Am J Respir Crit Care Med. 2006; 173: 1248-1254.

21. Klok MD, Jakobsdottir S, Drent ML. The role of leptin and ghrelin in the regulation of food intake and body weight in humans: a review. Obes Rev 2007; 8: 21-34.

22. Billington CJ, Briggs JE, Grace M, Levine AS. Effects of intracerebroventricular injection of neuropeptide Y on energy metabolism. Am J Physiol 1991; 260: R321-327.

23. Collins LC, Cornelius MF, Vogel RL, Walker JF, Stamford BA. Effect of caffeine and/or cigarette smoking on resting energy expenditure. Int J Obes Relat Metab Disord 1994; 18: 551-556.

24. Collins LC, Walker J, Stamford BA. Smoking multiple high- versus low-nicotine cigarettes: impact on resting energy expenditure. Metabolism 1996; 45: 923-926.

25. Christie D, Viner R. Adolescent development. BMJ 2005; 330 (7486): 301-304.

26. Bae J, Joung H, Kim JY, Kwon KN, Kim Y, Park SW. Validity of self-reported height, weight, and body mass index of the Korea Youth Risk Behavior Web-based Survey questionnaire. J Prev Med Public Health 2010; 43 (5): 396-402.

Received June 4, 2011. Accepted June 26, 2012. 